\title{
National perspective of acute coronary care in the Republic of Ireland
}

Council on Acute Coronary Care of the Irish Heart Foundation, Ballsbridge, Dublin

Department of Cardiology, St James' Hospital P A O'Callaghan M J Walsh

Department of Preventive Medicine, St Vincent's Hospital D M Comerford N Hickey

Department of Cardiology, Meath and Adelaide Hospitals

I M Graham

Department of Cardiology, Adelaide Hospital

I Higgins

Department of Public Health and

Epidemiology,

University College

LE Daly

Department of Electrophysiology,

The Cleveland Clinic

Foundation,

Cleveland, Ohio, USA

K Robinson

Irish Heart

Foundation

$M$ McLoughlin

Health and Screening Promotion, Charlemont Clinic D Kilcoyne

${ }^{\star}$ Dr Hickey died on 23 November 1993.

Correspondence to:

Dr M J Walsh, Department of Cardiology, CREST Hospital, Dublin 8, Ireland Accepted for publication 20 December 1994

Peter A O'Callaghan, Denise M Comérford, Ian M Graham, Isabella Higgins, Leslie E Daly, Killian Robinson, Mary McLoughlin, David Kilcoyne, Noel Hickey, Michael J Walsh

\begin{abstract}
Objective-To assess the use of acute coronary care facilities in the Republic of Ireland with regard to case mix, patient characteristics, mortality and factors associated with mortality, time intervals to admission, utilisation of thrombolysis, and risk factor profiles.

Design-A 1 week prospective census of all hospitals admitting acute coronary cases. These comprised 23 coronary care units (CCU) and 17 combined coronary care/intensive care units (CCU/ICU). Data were collected by standardised methods on each new patient "upon whom a cardiac monitor was placed".

Results-Acute coronary heart disease was confirmed in $185(44.9 \%)$ of 412 patients. Of these $109(26.4 \%)$ had a confirmed myocardial infarction and 76 $(18 \cdot 4 \%)$ unstable angina. Women were significantly older than men in all groups. Of those with proven acute coronary heart disease, $42 \cdot 6 \%$ were current smokers, $23 \cdot 1 \%$ were aware of having a raised cholesterol concentration, and $42.3 \%$ gave a history of prior hypertension. Only $44 \%$ were transported by ambulance. Median delay time from the onset of symptoms to admission was $6 \mathrm{~h}$ in Dublin and $4 \mathrm{~h}$ elsewhere. $34.9 \%$ of patients with a confirmed myocardial infarction received thrombolysis. Mortality of patients with myocardial infarction in CCU/ICU at 7 days was $10.9 \%$.

Conclusions-There is potential for considerable improvement in the management of coronary heart disease in the Republic of Ireland through a reduction in delay times to admission to hospital, increased use of thrombolytic treatment, and intensification of advice on primary and secondary risk factors.
\end{abstract}

(Br Heart f 1995;73:576-580)

Keywords: Republic of Ireland; coronary care units; coronary heart disease; thrombolytic treatment

Although the clinical entity of acute myocardial infarction was described in $1912,{ }^{1}$ it was not until the 1960 s, with the development of coronary care units, ${ }^{2}$ that effective treatment began to emerge. Closed chest cardiac massage $^{3}$ and direct current defibrillation ${ }^{4}$ were major advances. Many attempts were made to limit infarct size before the convincing demonstration that most myocardial infarctions are indeed caused by coronary thrombosis ${ }^{5}$ set the scene for the use of thrombolysis. Initial intracoronary thrombolysis $^{6}$ was rapidly replaced by intravenous use of such agents, with the demonstration of clinically significant reductions in mortality. ${ }^{7-9}$

One half of patients suffering a fatal coronary event die within $2 \mathrm{~h}$ of the onset of symptoms, ${ }^{10}$ often of ventricular fibrillation. The resultant emphasis on early initiation of acute coronary care was further stimulated by the demonstration that early thrombolysis is most effective. ${ }^{7811}$ Such developments have changed the role of coronary care units (CCU) since the $1960 \mathrm{s.}^{12}$

Since 1979, a simple computerised register has been used to audit the results of acute coronary care at several hospitals in Dublin, Ireland. Nationally, however, little is known of the utilisation or results of coronary care facilities. This led us to propose a 1 week census of all units in the country treating acute coronary cases, based on the experience obtained from auditing our own activities. The aims of the project were to examine:

(a) The numbers, diagnoses, and characteristics of patients admitted to coronary care facilities in Ireland;

(b) coronary care/intensive care unit (CCU/ICU) mortality and factors associated with mortality;

(c) the utilisation of thrombolysis;

(d) time intervals from onset of symptoms to admission; and

(e) risk factor profiles of patients with proven acute coronary heart disease.

\section{Methods}

Data collection forms were designed to be as simple as possible while providing essential information. A pilot study in three hospitals indicated that information could be readily obtained by nursing staff.

All hospitals in the country which handled coronary cases were contacted by telephone to ascertain whether they had CCU or combined CCU/ICU. Forty units were identified of 
which 23 had CCU facilities and 17 combined CCU/ICU. Preliminary estimates suggested that about 500 suitable patients are admitted to CCU or CCU/ICU each week, of whom about half have coronary disease. A week was taken as the census period as a sample of 250 coronary cases would give at least $80 \%$ power at a $5 \%$ significance level to detect percentage differences of $18 \%$ or more between equal sized groups; $95 \%$ confidence limits on proportions would also be within at least $\pm 7 \%$ of the sample value.

Each admitting consultant and unit sister was sent written details of the project and permission to conduct the census in their unit was obtained. Each unit was provided with a pack containing a poster, self-duplicating data collection forms, detailed instructions regarding definitions of terms and completion of the forms, and envelopes to return completed forms. Each sister was contacted before and during the census week to ensure understanding and full participation. From 0900 on 29 April 1992 to 0900 on 5 May 1992 each new patient "upon whom a cardiac monitor was placed" had a data collection sheet completed by the sister or senior staff nurse. Patients were questioned about their risk factor status and whether they were ever told that their cholesterol concentration or blood pressure was raised. Patients who had a parent or sibling with a history of angina or myocardial infarction were considered to have a family history of heart disease and those who had smoked any tobacco within the previous six months were considered to be current smokers.

Proven acute coronary heart disease (CHD) was defined as a case with objective evidence of myocardial infarction or unstable angina. Myocardial infarction was defined as cardiac pain at rest with either typical new $Q$ waves or at least a twofold increase in cardiac enzymes. Unstable angina was defined as cardiac pain at rest with $T$ wave changes on serial electrocardiogram with a less than twofold increase in cardiac enzymes.

Daily mortality was calculated using the life table method up to 7 days from admission. The estimate was unbiased because of the distribution of deaths and discharges. The $t$ and $\chi^{2}$ tests were used for comparison of means and proportions with exact $p$ values presented. Comparisons were based on medians using the Wilcoxon rank sum test because of the large skew in delay times. Confidence intervals for proportions were based on normal approximation for sample sizes above 100 and on exact binomial distribution otherwise.

\section{Results}

Figure 1 shows the distribution of admission and discharge diagnoses. Of 412 admissions, 230 patients $(55 \cdot 8 \%)$ were suspected of having acute coronary heart disease (CHD) which was subsequently confirmed in 185 (44.9\% of all admissions and $80.4 \%$ of those initially thought to have acute $\mathrm{CHD}$ ). Of these, $109(26.4 \%$ of all admissions) had a confirmed myocardial infarction and 76

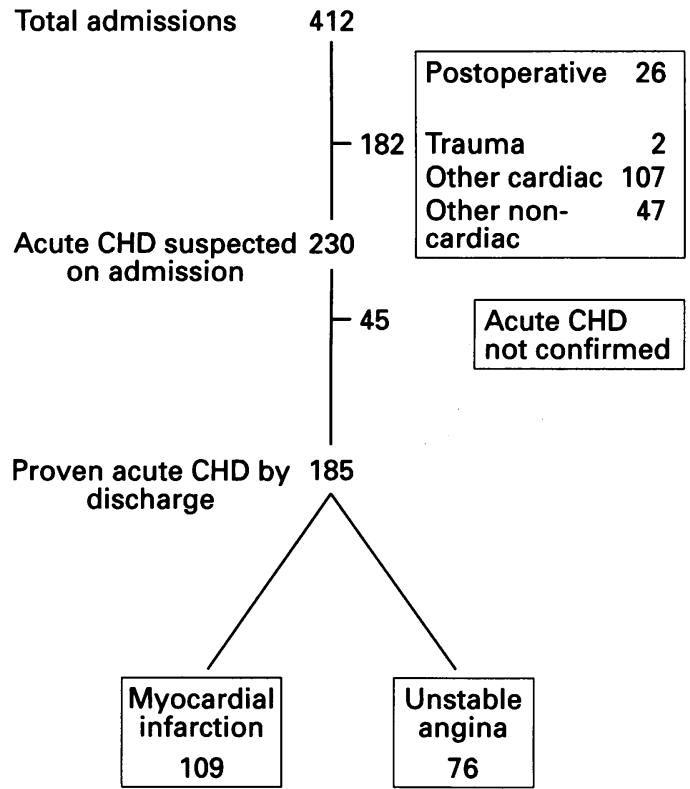

Figure 1 Distribution of admission and discharge diagnoses.

(18.4\%) unstable angina. A further 107 patients in whom acute coronary heart disease was not suspected were admitted with "other cardiac" problems. The majority of these patients were admitted for management of arrhythmia. Twenty one patients $(5 \cdot 1 \%)$ were readmitted to the unit during the survey week.

A total of 224 beds were available in the 40 units, about one bed for 15000 of the population. The mean number of beds for each unit was 5.6. On average 10.3 cases (range 3-19) were admitted to each unit during the survey week. The duration of stay of those patients discharged expressed as a mean (median) was: all patients $3 \cdot 1$ (2) days; myocardial infarction group $4 \cdot 8$ (4) days; and unstable angina group $2 \cdot 8$ (2) days. The majority were then transferred to recovery areas.

Table 1 shows the age, sex, and CCU/ICU mortality of all admissions and of those with proven acute CHD. Women were significantly older than men in all groups.

Some 185 patients had proven acute CHD. Admission was associated with the patient's first episode of acute CHD in $56 \%$ of cases. Employment status was obtained in 183 cases (data missing in two). Forty seven patients $(25.7 \%)$ were in current employment on admission with 16 (64\%) of 25 under 50 years of age employed. Some 101 patients $(55 \cdot 2 \%)$ were retired and $35(19 \cdot 1 \%)$ unemployed. There was a smaller percentage employed and a greater percentage retired compared with that of age and sex matched national values of $33 \%$ employed, $29 \%$ retired, and $38 \%$ unemployed. ${ }^{13}$ The highest level of education achieved was assessed in 171 cases (data missing in 14). Eleven $(6 \cdot 4 \%)$ had achieved third level education, $62(36.3 \%)$ secondary level, and $98(57 \cdot 3 \%)$ left school at primary level (age about 14 years).

Table 2 presents risk factor information of those with proven acute coronary heart 
Table 1 Demographic profile of admissions

\begin{tabular}{|c|c|c|c|c|}
\hline Study groups & $\begin{array}{l}\text { No of } \\
\text { patients }\end{array}$ & $\begin{array}{l}\text { Mean } \\
\text { Age (years) }\end{array}$ & $\begin{array}{l}\text { No of } \\
\text { deaths }\end{array}$ & $\begin{array}{l}\text { Mortality \% (95\% } \\
\text { Confidence Interval)* }\end{array}$ \\
\hline \multicolumn{5}{|l|}{ All patients } \\
\hline Male & 245 & $60 \cdot 8$ & 12 & $4.9(2.6-8.4)$ \\
\hline Female & 167 & $64 \cdot 3$ & 12 & $7 \cdot 2(3 \cdot 8-12 \cdot 2)$ \\
\hline Total & 412 & $\begin{array}{l}62.2 \\
P=0.025 t\end{array}$ & 24 & $\begin{array}{l}5.8(3.8-8.5) \\
P=0.33+\end{array}$ \\
\hline \multicolumn{5}{|c|}{ Myocardial infarction } \\
\hline Male & 69 & $60 \cdot 5$ & 6 & $8 \cdot 7(3 \cdot 3-18 \cdot 0)$ \\
\hline Female & 40 & $67 \cdot 9$ & 7 & $17 \cdot 5(7 \cdot 3-32 \cdot 8)$ \\
\hline Total & 109 & $63 \cdot 2$ & 13 & $11.9(5.8-18.0)$ \\
\hline \multicolumn{2}{|c|}{ Unstable angina } & $P=0.006 \dagger$ & & $P=0 \cdot 172 \dagger$ \\
\hline $\begin{array}{l}\text { Unstable an } \\
\text { Male }\end{array}$ & 42 & $61 \cdot 2$ & 0 & $0-$ \\
\hline Female & 34 & $69 \cdot 8$ & 0 & $0-$ \\
\hline Total & 76 & $65 \cdot 1$ & 0 & $0-$ \\
\hline
\end{tabular}

^ Confidence intervals expressed as percentages.

$\dagger$ Male $v$ female.
Table 2 Risk factor levels in acute coronary heart disease

\begin{tabular}{|c|c|}
\hline Risk Factor & $\begin{array}{l}\text { No of patients (\%) } \\
(95 \% \text { Confidence interval) * }\end{array}$ \\
\hline \multicolumn{2}{|l|}{ Smoking $(n=183)$} \\
\hline Current & $78(42 \cdot 6)(35 \cdot 5-49 \cdot 8)$ \\
\hline Ex-smoker & $55(30 \cdot 1)(23 \cdot 4-36 \cdot 7)$ \\
\hline \multicolumn{2}{|l|}{ History of raised cholesterol } \\
\hline History of raised blood & \\
\hline \multicolumn{2}{|l|}{$\begin{array}{l}\text { pressure }(n=182) \\
\text { Family history of }\end{array}$} \\
\hline $\begin{array}{l}\text { Family history of } \\
\mathrm{CHD}(\mathrm{n}=183)\end{array}$ & $104(56 \cdot 8)(49 \cdot 7-64 \cdot 0)$ \\
\hline
\end{tabular}

* Confidence intervals expressed as percentages.

disease. Some 78 of $183(42 \cdot 6 \%$ (95\% CI $35 \cdot 5-49 \cdot 8 \%)$ ) patients were current smokers, significantly higher than the mean of $33.4 \%$ based on national data for Irish adults of 30-69 years. ${ }^{14}$ Men were more likely to smoke than women $(51 \% v 30 \%, P=0.005)$ and in both sexes an inverse relation to age was noted, for example, 16 (73\%) of the 22 men aged under 50 years were smokers. Nearly one quarter of patients were aware of having had a raised cholesterol level and $42 \%$ gave a history of prior hypertension. A history of hyperlipidaemia was twice as common in those with a previous history of CHD as in those without this condition. There were no clear age or sex relations with past history of hyperlipidaemia, hypertension, or family history of CHD.

Less than half of patients with acute CHD (44\%) were admitted by ambulance. Some
$40 \%$ were driven by car. The remainder drove themselves or used other modes of transport.

\section{PATIENTS WITH MYOCARDIAL INFARCTION}

There were 13 deaths among the 109 patients with a myocardial infarction. This gives a crude mortality of $11.9 \%$ over a median hospital stay of 4 days (table 1). Using life table methods the $24 \mathrm{~h}$ mortality was $5 \cdot 5 \%$ (95\% CI $1 \cdot 2-9 \cdot 8 \%)$ and the 7 day mortality was $10 \cdot 9 \%(95 \%$ CI $4 \cdot 7-17 \cdot 1 \%)$. There were two further deaths at days 8 and 13. Crude mortality for women with myocardial infarction was substantially greater than that of men but failed to reach significance $(17.5 \% v 8 \cdot 7 \%, \mathrm{P}=$ $0 \cdot 172)$. Mortality of patients with myocardial infarction increased significantly with age. In those aged under 60 years $(n=37)$ there were no deaths, in those aged 60-69 mortality was $11.1 \%$ (four of 36 ), and in those aged 70 or above $25.0 \%$ (9 of 36$)(P=0.004)$. There were no deaths in patients with unstable angina.

Table 3 gives the median delay time from onset of symptoms to admission to CCU/ICU in patients with myocardial infarction. Figure 2 shows cumulative percentages of patients with myocardial infarction admitted at different time intervals. Overall, 70 of 108 (65\% (95\% CI $55 \cdot 8-73 \cdot 8 \%)$ ) patients with myocardial infarction were admitted within $6 \mathrm{~h}$ of the onset of chest pain. Patients outside Dublin were admitted more rapidly than those in Dublin (median delay time $4 v 6 \mathrm{~h}, \mathrm{P}=$ 0.004 ), with $46 \%$ reaching hospital within $3 \mathrm{~h}$ of the onset of symptoms. Further subgroup analysis is difficult because of the small numbers in each group. Females with myocardial infarction, however, tended to reach hospital more rapidly than males (median delay time 4 $v 5 \mathrm{~h}, \mathrm{P}=0.607$ ).

The use of thrombolysis is also shown in table 3 . Some $34.9 \%$ of patients with confirmed myocardial infarction received thrombolytic treatment. Men received thrombolytic treatment more often than women and those admitted to Dublin hospitals received thrombolytic treatment significantly more often than those admitted to non-Dublin hospitals. Thrombolysis was also related to the delay time to admission. Twenty eight $(40.0 \%)$ of 70 of those with delay times less than $6 \mathrm{~h}$

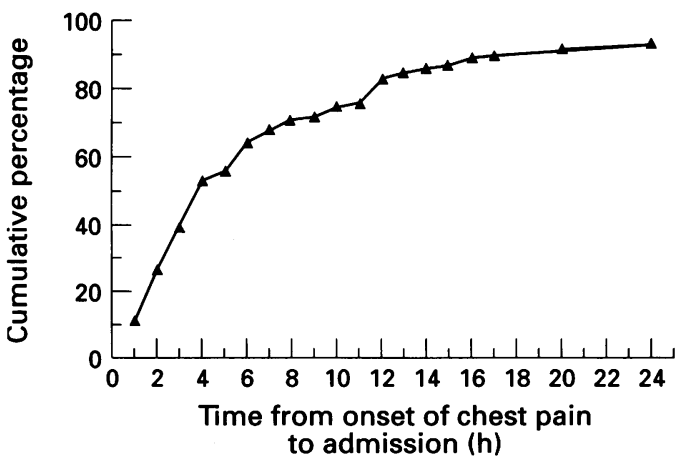

Figure 2 Cumulative percentage of patients with myocardial infarction admitted to CCU or CCU/ICU at various time periods from the onset of symptoms. CHD, coronary heart disease.
Table 3 Delay times to admission and use of thrombolytic treatment in patients with Myocardial Infarction

\begin{tabular}{lll}
\hline & $\begin{array}{l}\text { Administration of } \\
\text { thrombolytic treatment } \\
\text { No of patients }(\%)(95 \% \\
\text { Confidence interval) }\end{array}$ & $\begin{array}{l}\text { Median } \\
\text { delay time }(h) t\end{array}$ \\
\hline $\begin{array}{l}\text { Patients admitted in Dublin }(\mathrm{n}=35) \\
\text { Patients admitted from outside }\end{array}$ & $17(48 \cdot 6)(31 \cdot 4-66 \cdot 0)$ & 6 \\
$\quad$ Dublin $(\mathrm{n}=74)$ & $21(28 \cdot 4)(18 \cdot 5-40 \cdot 01)$ & 4 \\
Males admitted to hospital $(\mathrm{n}=69)$ & $\mathrm{P}=0 \cdot 039 \ddagger$ & $\mathrm{P}=0.004 \ddagger$ \\
Females admitted to hospital $(\mathrm{n}=40)$ & $10(40 \cdot 6)(28 \cdot 9-53 \cdot 1)$ & 5 \\
Total $(\mathrm{n}=109)$ & $\mathrm{P}=0 \cdot 100 \$(12 \cdot 7-41 \cdot 2)$ & 4 \\
\hline
\end{tabular}

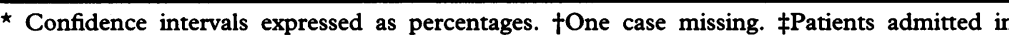
Dublin $v$ those admitted from outside Dublin. SMale $v$ female. 
received thrombolysis compared with $26.3 \%$ (10 of 38 ) in those with longer delay times $(P=0 \cdot 155)$. Some $63.2 \%$ (12 of 19) of Dublin admission with delay times under $6 \mathrm{~h}$ received thrombolysis. In only six cases was thrombolysis administered in the accident and emergency department. None of the 38 patients with myocardial infarction given thrombolytic treatment died compared with $13(18.3 \%)$ of the 71 who did not receive such treatment $(P=0.010)$.

\section{Discussion}

To our knowledge there are no other reports of the utilisation of coronary care facilities throughout a whole country over a predefined time period. The national census proved relatively easy to organise and administer and was received enthusiastically by participants. Some $56 \%$ of patients were suspected of having acute CHD on admission. Given that 17 units had combined CCU/ICU and that other acute cardiac problems were also admitted, this would seem an appropriate use of an expensive health resource. Subsequent investigation proved the initial diagnosis of acute CHD to be correct in $80 \%$ of cases. Our own units do not exclude patients on the basis of age and it is thought that few units nowadays do so. The mean age of patients admitted does not suggest an excessive burden of very elderly subjects (table 1), although women with CHD were substantially older than men.

Mortality in CCU is the product of age, infarct size, delay time to admission, and treatment employed. The overall mortality of patients with myocardial infarction in CCU/ICU was $11.9 \%$ and is comparable with that of other series. ${ }^{15}$ Women with myocardial infarction were noted to have a higher mortality than men. This has been found in other series. ${ }^{16}$ The adverse experience of women may be explained by their greater age rather than a gender effect per se. ${ }^{17}$

A substantial proportion of subjects were retired and most left school after primary level education. Lesser education is a proxy for lower socioeconomic group and such patients are more likely to experience higher CHD mortality, a greater burden of coronary risk factors, and to have greater difficulty responding to risk factor advice. ${ }^{18}$ An appreciable proportion of patients may have been aware of their risk factor status in that about $43 \%$ were smokers, $23 \%$ were aware of being hyperlipidaemic, and $42 \%$ gave a history of hypertension. Some $57 \%$ had a family history of $\mathrm{CHD}$ and $73 \%$ of men under 50 years smoked.

Some $65 \%$ of patients with myocardial infarction reached hospital within $6 \mathrm{~h}$ of the onset of symptoms and approximately $80 \%$ within $12 \mathrm{~h}$. Dublin patients took longer to be admitted than those outside Dublin, particularly in the case of women. Median delay times in this census were similar to those reported in a recent Irish study. ${ }^{19}$ These data are not impressive; in Edinburgh, for example, two thirds of patients present to the
Royal Infirmary within $2 \mathrm{~h}$ of the onset of symptoms. ${ }^{20}$. These delay times may be exaggerated by the fact that the time intervals were to the CCU/ICU as opposed to the accident and emergency department, but they remain a cause for concern. It is likely that education of the general public and physicians, improvements in the ambulance service, and provision of. a "fast-track" admission system would reduce these delays. Further examination, however, of patient, physician, and ambulance response times, and means of transport to hospital is required.

Overall, thrombolytic treatment was given to one third of patients with confirmed myocardial infarction. This is greater than the percentage given such treatment in most large clinical trials. ${ }^{21}$ These data should be interpreted with caution as they relate to confirmed myocardial infarction rather than conventional criteria for thrombolysis. Nevertheless, the use of thrombolysis seems modest. This may in part reflect the relatively long delay times to admission. Only six patients received thrombolysis in the accident and emergency department; the number of departments operating a "fast-track" policy is not known.

We conclude that the utilisation of coronary care facilities in Ireland seems appropriate and that most initial diagnoses of acute CHD are correct. Mortality, at least in men, is low but it is likely that in view of the fairly long delay times to admission many patients die outside hospital. This national census highlights the need to reduce delay times and to increase the utilisation of thrombolytic treatment in patients with acute myocardial infarction. Many patients admitted to CCU already have sufficient information to allow risk factor modification. While the understanding and use of such information were not studied, there is likely to be considerable scope to intensify primary and secondary preventive efforts. We thank the sisters, nurses, and physicians of the participating
hospitals for their unstinting support and enthusiasm. This project would not have been possible without their help. We also acknowledge the support of the Irish Heart Foundation.

1 Herrick JB. Clinical features of sudden obstruction of the coronary arteries. $\mathcal{F} A M A 1912 ; 59: 2015-20$.

2 Day $\mathrm{HW}$. Preliminary studies of an acute coronary care area. Lancet 1963;83:53-5.

3 Kouwenhoven WB, Jude JR, Knickerbocker GG. Closed chest cardiac massage. $\mathcal{F} A M A 1960 ; 173: 1064-7$.

4 Lown B, Amarasingham R, Neuman J. New method for terminating cardiac arrhythmias. Use of synchronised capicitor discharge. $¥ A M A$ 1962;182:548-55.

5 DeWood MA, Spores J, Notske R, Mouser LT, Burroughs $\mathrm{R}$, Golden MS, et al. Prevalence of total coronary occlusion during the early hours of transmural myocardial infarction. N Engl f Med 1980;303:897-902.

6 Kennedy JW, Ritchie JL, Davis KB, Stadius ML, Maynard $C$, Fritz JK. The Western Washington randomised trial of Fitracoronary streptokinase in acute myed trial infarction. A twelve month follow-up report. $N$ Engl $f$ Med 1985;312(17):1073-8.

7 Effectiveness of intravenous thrombolytic treatment in acute myocardial infarction. Gruppo Italiano per lo Studio della Streptochinasi nell'Infarto Miocardico Studio della Streptochinasi nell

8 Randomised trial of intravenous streptokinase, oral aspirin, both, or neither among 17187 cases of suspected acute both, or neither among 17187 cases of suspected acu
myocardial infarction: ISIS-2. Lancet 1988;ii:349-60.

9 Long-term effects of intravenous anistreplase in acute Long-term effects of intravenous anistreplase in acute
myocardial infarction: final report of the AIMS study. Lancet 1990;335:427-31. 
10 McNeilly RH, Pemberton J. Duration of last attack in 998 fatal cases of coronary artery disease and its relation to possible cardiac resuscitation. BMF 1968;3:139-42.

11 Rovelli F, De Vita C, Feruglio GA, Lotta A, Selvini A Tognoni G. GISSI trial: early results and late followup. Gruppo Italiano per la Sperimentazione della up. Gruppo Italiano per la Sperimentazione della Cardiol 1987;10(5 suppl B):33-9B.

12 Walsh MJ. The coronary care unit: a reappraisal. Ir Med $\mathcal{F}$ 1987;80(12):394-6.

13 Census 86. Summary population report-2nd series. Dublin: Stationery Office, 1989

14 Irish Heart Foundation. Happy heart national survey: a report on health behaviour in Ireland. Dublin: Irish Heart Foundation, 1994.

15 Weaver WD, Litwin PE, Martin JS, Kudenchuk PJ, Maynard C, Eisenberg MS, et al. Effect of age on use of thrombolytic therapy and mortality in acute myocardial infarction. F Am Coll Cardiol 1991;18(3): 657-62.

16 Stevenson R, Ranjadayalan K, Wilkinson P, Roberts R,
Timmis AD. Short and long term prognosis of acute myocardial infarction since introduction of thrombolysis. $B M F$ 1993;307:349-52.

17 Robinson K, Conroy RM, Mulcahy R, Hickey N. Risk factors and in-hospital course of first episode of myocardial infarction or acute coronary insufficiency in women. infarction or acute coronary insuff

18 Mulcahy R, Daly L, Graham I, Hickey N. Level of education, coronary risk factors and cardiovascular disease. Ir Med $\mathcal{f} 1984 ; 77(10): 316-8$.

19 McGee HM, O'Callaghan D, MacGowan GA, Horgan JH and the Irish ISIS-2 collaborators. Factors associated with delay to treatment for acute myocardial infarction in Ireland. Ir Med f. 1994;87:187-8.

20 Pell AC, Miller HC. Delays in admission of patients with acute myocardial infarction to coronary care: implications of thrombolysis. Health Bull (Edinb) 1990;48: 225-31.

21 Muller DW, Topol EJ. Selection of patients with acute myocardial infarction for thrombolytic therapy. Ann Intern Med 1990;113(12):949-60.

\section{NOTICE}

The Second International Heart Health Conference is being held in Barcelona from 28 May to 1 June 1995. Further details are available from Meree Ferrer, Congress Secretariat, Pacifico SA, E Granados 44, 08008 Barcelona, Spain (tel: 00343454 5400, fax: 003434517438 ). 